\title{
Solvent mixture effect in the zinc hexacyanoferrate (III) nanoparticles: Synthesis, characterization and voltammetric application
}

\author{
Devaney Ribeiro Do Carmo*, Daniela Silvestrini Fernandes, Loanda Raquel Cumba, \\ Mariana de Souza Magossi, Vanessa Solfa dos Santos \\ Faculdade de Engenharia de Ilha Solteira UNESP - Univ. Estadual Paulista, Departamento de Física e Química, Av. Brasil Centro, 56 CEP 15385-000, Ilha \\ Solteira, SP, Brazil
}

\section{A R T I C L E IN F O}

\section{Article history:}

Received 5 March 2016

Received in revised form 1 August 2016

Accepted 23 August 2016

Available online 24 August 2016

\section{Keywords:}

Nanostructures

Chemical synthesis

X-ray diffraction

Electron microscopy

Electrochemical properties

\begin{abstract}
A B S T R A C T
This work describes the preparation and characterization of size-controlled zinc hexacyanoferrate (III) nanoparticles $(\mathrm{ZnH})$. They were prepared using different proportions of water/formamide in the complexation reaction of $\mathrm{Zn}^{2+}$ with $\left[\mathrm{Fe}^{\mathrm{III}}(\mathrm{CN})_{6}\right]^{3-}$. The materials were characterized by Fourier Transform Infrared Spectroscopy (FT-IR), Ultraviolet-Visible Spectroscopy (UV-vis), X-ray Diffraction (XRD), Scanning Electron Microscopy (SEM), Energy Dispersive X-ray Spectroscopy (EDX) and Cyclic Voltammetry (CV). The cyclic voltammograms of the modified graphite paste electrode with $\mathrm{ZnH}-1$, $\mathrm{ZnH}-2, \mathrm{ZnH}-3$ and $\mathrm{ZnH}-4$ showed a well-defined redox couple with formal potential $\left(\mathrm{E}^{\theta^{\prime}}\right)=0.94 \pm 0.01 \mathrm{~V}$ $\left.\left(\nu=20 \mathrm{mV} \mathrm{s}^{-1} ; \mathrm{KCl} 1.0 \mathrm{M}\right)\right)$ attributed to the redox process $\left[\mathrm{Fe}^{\mathrm{II}}(\mathrm{CN})_{6}\right] /\left[\mathrm{Fe}^{\mathrm{III}}(\mathrm{CN})_{6}\right]$ in the presence of $\mathrm{Zn}^{2+}$. The dependence of particle size on the detection of sulfite was verified.
\end{abstract}

(c) 2016 Elsevier Ltd. All rights reserved.

\section{Introduction}

The synthesis of metal nanoparticles (NPs) or nanostructured materials with different morphologies is currently a research area of intense scientific interest. Due to its highly active surface morphology, these novel materials can exhibit remarkable chemical and physical properties that are different from both the ion and the bulk material [1-3]. From a synthetic point of view, the main challenge is to seek new procedures that allow the preparation of nanoparticles in a controlled manner, obtaining (i) a narrow size distribution, because the properties of nanoparticles are highly size dependent, (ii) protection against aggregation, and (iii) a wide range of chemical compositions [4]. The various methods to synthesize transition metal NPs were extensively reviewed by Rothemberg [5] and numerous types of inorganic NPs have been synthesized and investigated. Among inorganic nanoparticles, metal hexacyanoferrates (MHCFs) have been the subject of increasing interest due to their important properties in solid state batteries [6,7], electrocatalysis [8,9], catalysis [9,10], electroanalytical applications [11,12], magnetism [13] photothermal ablation agents for cancer therapy [14], photoisomerization [15] and others [16].

\footnotetext{
* Corresponding author.

E-mail address: docarmo@dfq.feis.unesp.br (D.R. Do Carmo).
}

Metal hexacyanoferrates are polynuclears and have an open channel structure [17-19]. These complexes do not dissolve in the oxidation/reduction process and allow the ions to diffuse into/out of their zeolitic structures in order to maintain electrical charge neutrality [20,21].

Unlike the other Prussian blue analogues [22], zinc hexacyanoferrate (III) (ZnHCF) stands out as a unique exception in that it cannot be deposited easily on surfaces like glassy carbon (GC), Pt and $\mathrm{Au}$, as procedures required for adhesion are too involved in nature [23-26]. In certain cases, ZnHCF films were obtained by electrochemical cycling of zinc electrodes in solutions containing ferricyanide [24], in which nascent $\mathrm{Zn}$ ions are produced during the anodic scan complex with ferricyanide in the solution. This behavior is an indicative of the lack of active sites crucial to its deposition on GC, Au and Pt.

Several attempts in were made during the past decade to generate PB and PBA NPs by different synthetic methods [27,28], such as reverse micelles, $[29,30]$ protective polymer techniques [31,32] and template [33]. Nevertheless, some of the methods for the synthesis of metal nanoparticles are not industrially viable; generally, these methods are inconvenient and environmentally unfriendly processes consuming enormous amounts of organic solvents.

In this paper, we report an easy and direct route for the synthesis to obtain zinc hexacyanoferrate (III) nanoparticles. They were prepared using different proportions of water/formamide in 
the complexation reaction of zinc ions with $\left[\mathrm{Fe}^{\mathrm{III}}(\mathrm{CN})_{6}\right]^{3-}$. We demonstrate that the particle size reflects the structural and electrochemical properties of the material. In addition, there are few reports available about nanoparticles of zinc hexacyanoferrate (III), mainly with regards to studies about the effect of morphology on the electrochemical behavior. As a practical application of the nanoparticles, this paper shows the size effect of ZnHCF nanoparticles on the electrocatalytic detection of sulfite.

\section{Experimental}

\subsection{Reagents and solutions}

All reagents and solvents were of analytical grade (Alpha Aesar, Merck or Aldrich) and were used as received (without further purification). All solutions were prepared using deionized water with resistivity no less than $18.2 \mathrm{M} \Omega \mathrm{cm}$. The solutions of sodium sulfite were prepared immediately before use.

\subsection{Preparation of nanoparticles of zinc Hexacyanoferrate(III)}

The nanoparticles were synthesized according to the procedure described in the literature [34], with some modifications described as follows: two solutions, $\mathrm{A}$ and $\mathrm{B}$, were prepared. Solution $\mathrm{A}$ consisted of $2.13 \times 10^{-3} \mathrm{~mol}$ of $\mathrm{K}_{3}\left[\mathrm{Fe}(\mathrm{CN})_{6}\right]$ dissolved in a solution of $30 \mathrm{~mL}$ of water and formamide mixture. Solution $\mathrm{B}$ was prepared by dissolving $2.72 \times 10^{-3} \mathrm{~mol}$ of $\mathrm{ZnCl}_{2}$ in $20 \mathrm{~mL}$ of water and formamide. Next, the solution A was poured into solution $\mathrm{B}$ and stirred for $2 \mathrm{~h}$. The solid phase was isolated by centrifugation $(1.500 \mathrm{rpm})$. Then the solid phase was filtered using a sintered plate funnel and washed exhaustively with deionized water thoroughly to eliminate the potassium chloride formed during the reaction. The materials were dried at $60^{\circ} \mathrm{C}$. To investigate the effect of formamide on the synthesis, four samples, $\mathrm{ZnH}-1, \mathrm{ZnH}-2$, $\mathrm{ZnH}-3$ and $\mathrm{ZnH}-4$, were synthesized in four reaction media with different water and formamide volume ratios, 10:0; 8:2; 4:6 and $0: 10$, respectively.

\subsection{Characterization measurements}

The vibrational spectra of the materials were obtained by a Nicolet 5DXB FT-IR spectrometer (Nicolet Instruments, Madison, WI). The pastilles for analysis were prepared using $150 \mathrm{mg}$ of $\mathrm{KBr}$ (previously dried) and $1.5 \mathrm{mg}(1.0 \%(\mathrm{~m} / \mathrm{m}))$ of each sample. A minimum of 64 "scans" with a resolution of $\pm 4 \mathrm{~cm}^{-1}$ in a band of $4000-400 \mathrm{~cm}^{-1}$ was used. The X-Ray diffraction characterization was carried out using Rigaku Ultima IV diffractometer with $\mathrm{Cu} \mathrm{Ka}$ radiation $(\lambda=1.5418 \AA$ ). Electronic spectra (UV-vis) were obtained using Guided Wave model 260 spectrophotometer, in the range of $350-1600 \mathrm{~nm}$. The microstructure was observed using a fieldemission scanning electron microscope (FE-SEM, JSM-6700 F, Japan).

\section{Results and discussion}

Zinc hexacyanoferrate (III) nanoparticles were easily prepared by mixing the solution of zinc ions with the solution of hexacyanoferrate ions from a solution containing water and formamide. Different water and formamide ratios were tested. Four systems ( $\mathrm{ZnH}-1-\mathrm{ZnH}-2, \mathrm{ZnH}-3, \mathrm{ZnH}-4)$ were prepared. The percentage of each constituent, for example, carbon, nitrogen, hydrogen, zinc and iron were determined by elemental analysis, atomic absorption and energy dispersed spectroscopy (EDS). Table 1 lists the data of elemental analysis. The results revealed that the molecular formula of Zinc hexacyanoferrate (III) for 4 systems were very close, and concluded that the synthesized
Table 1

Analytical data for systems.

\begin{tabular}{llll}
\hline & \multicolumn{2}{l}{ Atomic Percentage (\%) } & Ratio \\
\hline System & $\mathrm{Zn}^{2+}$ & $\mathrm{Fe}^{3+}$ & $\mathrm{Zn}^{2+} / \mathrm{Fe}^{3+}$ \\
ZnH-1 & 11.0 & 7.40 & 1.49 \\
ZnH-2 & 9.99 & 6.61 & 1.51 \\
ZnH-3 & 9.81 & 6.51 & 1.51 \\
ZnH-4 & 9.85 & 6.50 & 1.51 \\
\hline
\end{tabular}

compounds have a molecular formula of $\mathrm{Zn}_{3}\left[\mathrm{Fe}(\mathrm{CN})_{6}\right]_{2} \cdot \mathrm{nH}_{2} \mathrm{O}$. Eq. (1) describes the reaction which occurs for the formation of zinc hexacyanoferrate nanoparticles.

$2\left[\mathrm{Fe}(\mathrm{CN})_{6}\right]^{3-}+3 \mathrm{Zn}^{2+}+$ Solvent (water, formamide or mixture) $\leftrightarrows$ $\mathrm{Zn}_{3}\left[\mathrm{Fe}(\mathrm{CN})_{6}\right]_{2} \cdot \mathrm{nH}_{2} \mathrm{O}$

\subsection{The vibrational spectroscopy in the infrared region (FT-IR)}

The synthesized nanoparticles were initially characterized by FT-IR to determine the most important functional groups present in the synthesized products. Fig. 1 illustrates the infrared spectra of the potassium hexacyanoferrate (III) (a) and the four zinc hexacyanoferrate systems (b to e). In all spectra a strong band around $2100 \mathrm{~cm}^{-1}$ is observed, attributed to the $\mathrm{CN}$ group (stretching $v_{\mathrm{s}}(\mathrm{CN})$ ) present in the $\mathrm{Fe}^{\mathrm{III}}-\mathrm{CN}-\mathrm{Zn}^{\mathrm{III}}$. Another less intense absorption was also observed at $2162 \mathrm{~cm}^{-1}$, attributed to the free $\mathrm{CN}$ group. The band at $491 \mathrm{~cm}^{-1}$ corresponded to the $\mathrm{Zn}-\mathrm{N}$ group $[35,36]$. In the high frequency region, water molecules are associated with this complex and a broad peak was observed at $3631 \mathrm{~cm}^{-1}$ due to the presence of $\mathrm{OH}$ moiety from water molecules. Another peak at $1614 \mathrm{~cm}^{-1}$ is due to $\mathrm{HOH}$ bending. Lastly, the peak at $602 \mathrm{~cm}^{-1}$ corresponds to $\mathrm{Fe}-\mathrm{C}$ stretching [35]. For all systems, the formation of a cyan-bridged network was confirmed as attested by shift of stretching $v_{\mathrm{s}}(\mathrm{CN})$ with respect to the potassium hexacyanoferrate (III) precursor (a).

\subsection{The electronic spectra (UV-vis)}

Fig. 2 shows the diffuse reflectance UV-vis spectra for $\mathrm{ZnH}-1$, $\mathrm{ZnH}-2, \mathrm{ZnH}-3$ and $\mathrm{ZnH}-4$, after deconvolution. For zinc hexacyanoferrates two possible transitions are expected, a d-d transition

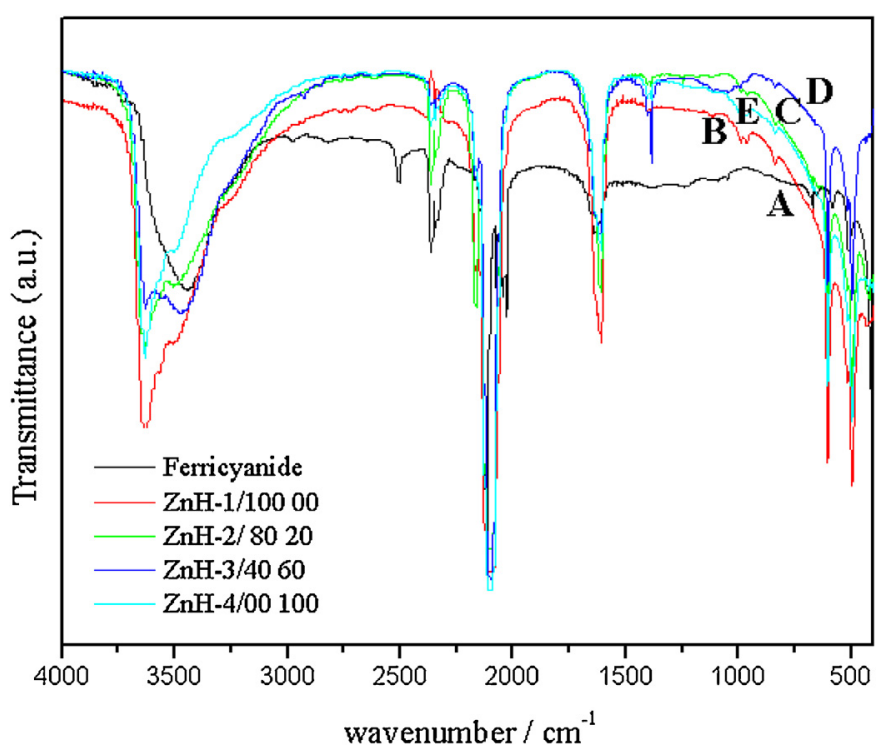

Fig. 1. FT-IR of system: (A) $\mathrm{ZnH}-1$; (B) $\mathrm{ZnH}-2$; (C) $\mathrm{ZnH}-3$ and (D) $\mathrm{ZnH}-4$. 

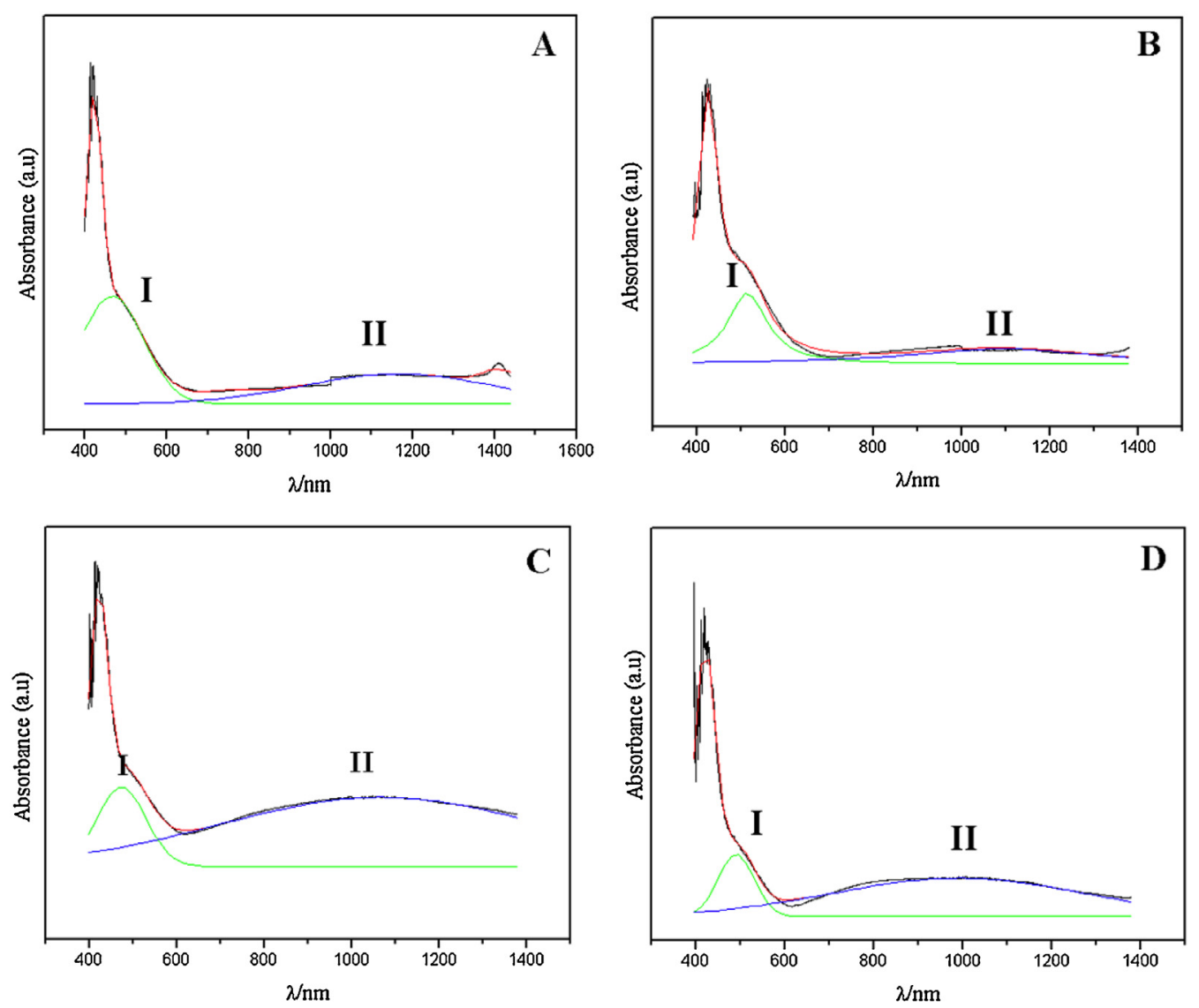

Fig. 2. Diffuse reflectance (UV/Vis) for the systems: (A) $\mathrm{ZnH}-1$; (B) $\mathrm{ZnH}-2$; (C) $\mathrm{ZnH}-3$ and (D) $\mathrm{Zn}-\mathrm{H}-4$.

within the low spin iron (III) atom and a metal to ligand charge transfer (MLCT) band from the latter one towards the CN groups [37]. The electronic spectra of the newly prepared materials were similar. A shoulder at $470 \mathrm{~nm}$ was observed and interpreted as resulting from the $\mathrm{d}-\mathrm{d}$ transitions. A broad intervalence chargetransfer band in the visible region between $600-1400 \mathrm{~nm}$ was also observed. The detail is that the maximum absorption band $\left(\lambda_{\max }\right)$ of the nanoparticles was blue-shifted, i.e., $\mathrm{ZnH}-4, \mathrm{ZnH}-3, \mathrm{ZnH}-2$ slightly shifted to shorter wavelengths from that of $\mathrm{ZnH}-1$. These data suggest that the particles exhibited size-quantization effects [34,38].

\subsection{X-Ray diffraction (XRD)}

Fig. 3 illustrates the X-ray diffraction measurements for all systems. The clear and sharp X-ray peaks indicated a high crystallinity of synthesized nanoparticles and clear presence of two phases, a hydrated (JCPDS card no. 38-687) and the other one less hydrated (JCPDS card no. 38.688). For the systems $\mathrm{ZnH}-1, \mathrm{ZnH}-$ 2 and $\mathrm{ZnH}-3$, the signal intensity peak centered at $2 \theta=14.8$ decreases and disappears in the pattern of $\mathrm{ZnH}-4$ system. This behavior is in good agreement with results obtained for nanoparticles of cobalt hexacyanoferrate [34] in aqueous/formamide solution. So by the Scherrer Eq. (2):

$\mathrm{d}=0.9 \lambda /(\mathrm{B} \cos \theta)$

$d$ is the grain diameter, $\lambda$ is the X-ray wavelength $(0.154 \mathrm{~nm}), B$ is the full width at half max (FWHM) and $\theta$ is Bragg angle.

Using FWHM of the main peak near $2 \theta=16.2$, the particle sizes were estimated to be $76.47 ; 57.58 ; 55.57$ and $68.07 \mathrm{~nm}$ for $\mathrm{ZnH}-1$,
$\mathrm{ZnH}-2$ and $\mathrm{ZnH}-4$, respectively. It was verified that the peaks broadened, indicating a decrease in the particle size when the water/formamide mixture was used. The peak near $2 \theta=17.1$ in the $\mathrm{ZnH}-1, \mathrm{ZnH}-2, \mathrm{ZnH}-3$ systems but not intense in the $\mathrm{ZnH}-4$ system indicates the presence of water molecules in the space between the octahedrons $\mathrm{Zn}_{3}\left[\mathrm{Fe}(\mathrm{CN})_{6}\right]_{2} \cdot \mathrm{xH}_{2} \mathrm{O}$, that crystallize into a cubic structure with the space group $\mathrm{Fm} 3 m$ [39]. The structure consists of two types of octahedrons $\left(\mathrm{ZnII}(\mathrm{NC})_{6}\right)$ and FeIII $\left.(\mathrm{CN})_{6}\right)$ arranged on a cubic lattice and linked by cyanide ligands. Water molecules, which contribute to the existence of structural disorder, appear in the space between the octahedrons [40].

\subsection{Scanning electron microscopy (SEM) and energy dispersive X-Ray spectroscopy (EDS)}

The surface morphology of zinc hexacyanoferrate (III) was evaluated by scanning electron microscopy (FEG-SEM), which revealed the shape and size of the synthesized products. The FEGSEM (Fig. 5) shows that the particles were predominantly irregular in shape with average size ranging from 50 to $200 \mathrm{~nm}$ (Fig. 5) for all systems. This estimate is consistent with the size values obtained by X-ray diffraction. The nanoparticles of $\mathrm{ZnH}-3$ and $\mathrm{ZnH}-4$ systems presented a more compact, homogeneous topology (see inset for all systems) and smooth surface, which indicates the water/formamide mixture has an important role.

The elemental composition of the synthesized nanoparticles were analyzed by energy dispersive spectroscopy (EDS) which showed the presence of $\mathrm{Zn}, \mathrm{Fe}, \mathrm{N}$, as illustrated by Fig. 4 .

The average ratio of $\mathrm{Zn}^{2+} / \mathrm{Fe}^{3+}$ was $1.50 \pm 0.01$ which is close to the expected value of 1.50 observed for the corresponding 

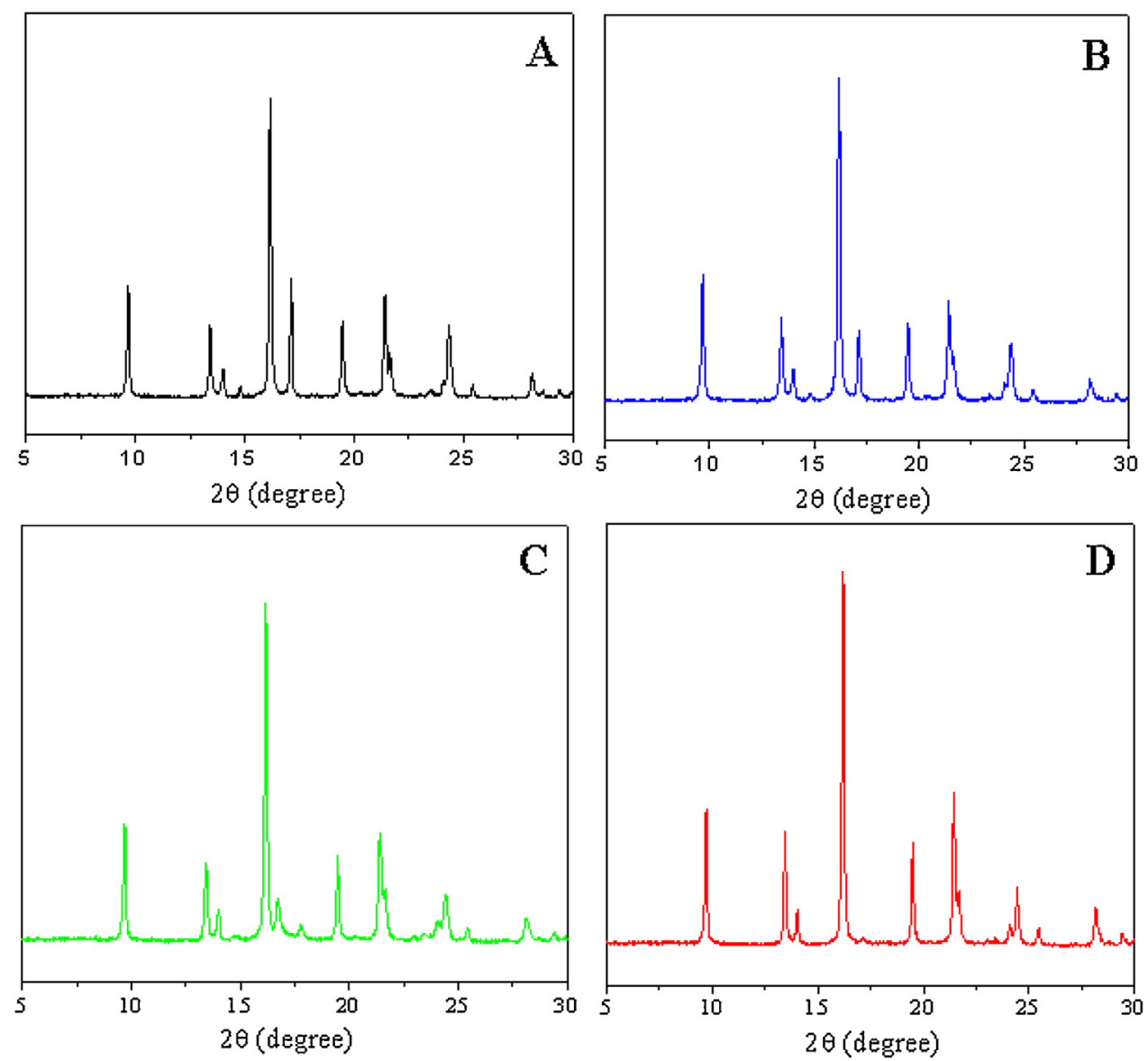

Fig. 3. X-ray diffractograms of systems: (A) $\mathrm{ZnH}-1$; (B) $\mathrm{ZnH}-2$; (C) $\mathrm{ZnH}-3$ and (D) $\mathrm{ZnH}-4$.

materials with formula $\mathrm{M}_{3}\left[\mathrm{Fe}(\mathrm{CN})_{6}\right]_{2} \cdot \mathrm{xH}_{2} \mathrm{O}$ [41]. Table 1 list these values for all systems. The results revealed the structure of synthesized zinc hexacyanoferrate was very close to $\mathrm{Zn}_{3}[\mathrm{Fe}$ $\left.(\mathrm{CN})_{6}\right]_{2} \cdot 2 \mathrm{H}_{2} \mathrm{O}$ which are in good agreement with the results obtained from atomic absorption.
Our results indicate that formamide has an important role in the control of the morphology and surface characteristics in the formation of the nanoparticle process. This fact is important because many physical and chemical properties are surface dependent, such as catalysis and electrocatalysis.

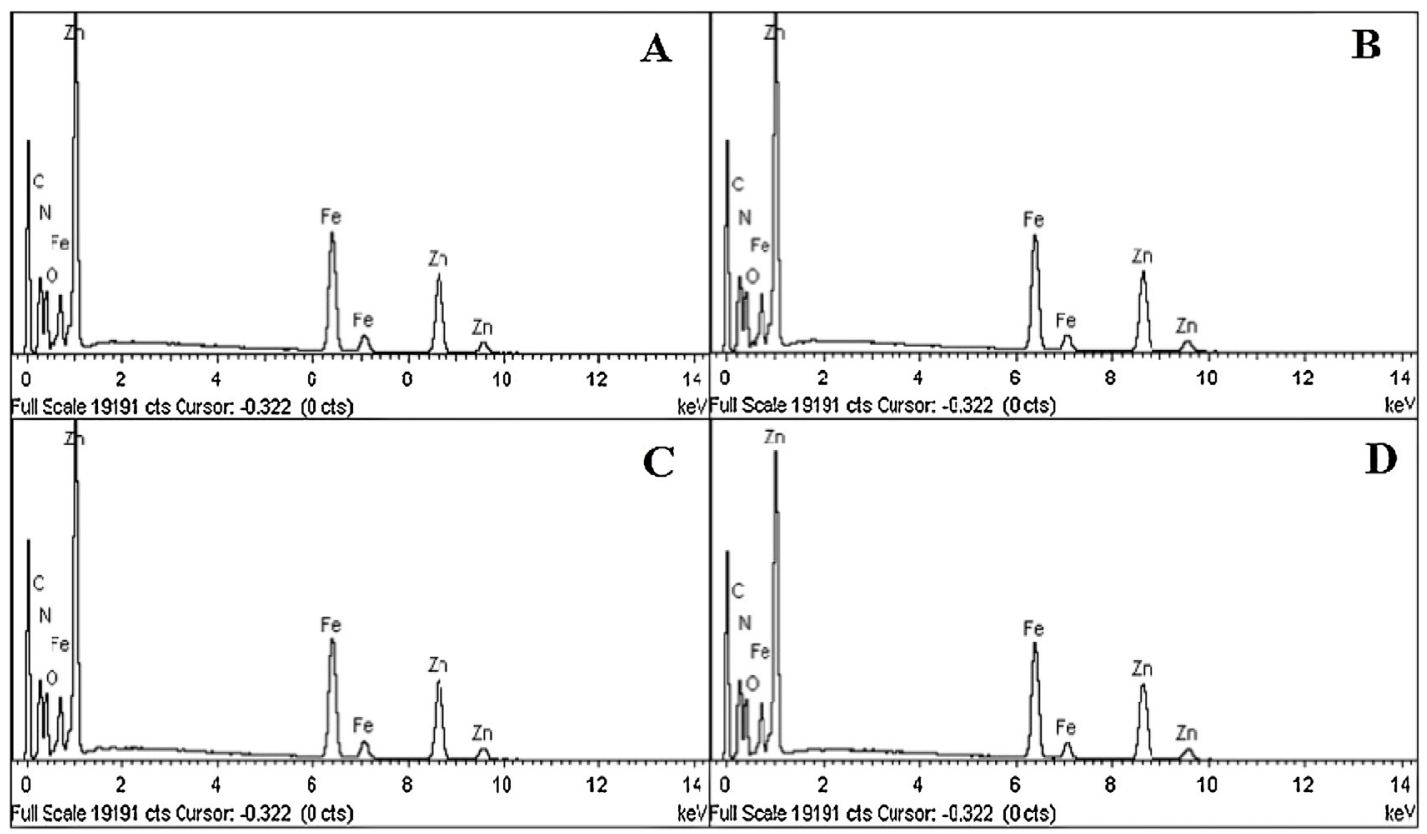

Fig. 4. EDS spectrum of $\mathrm{Zn}_{3}\left[\mathrm{Fe}(\mathrm{CN})_{6}\right]_{2} \cdot 2 \mathrm{H}_{2} \mathrm{O}$ nanoparticles of systems: (A) $\mathrm{ZnH}-1$; (B) $\mathrm{ZnH}-2$; (C) $\mathrm{ZnH}-3$ and (D) $\mathrm{ZnH}-4$. 

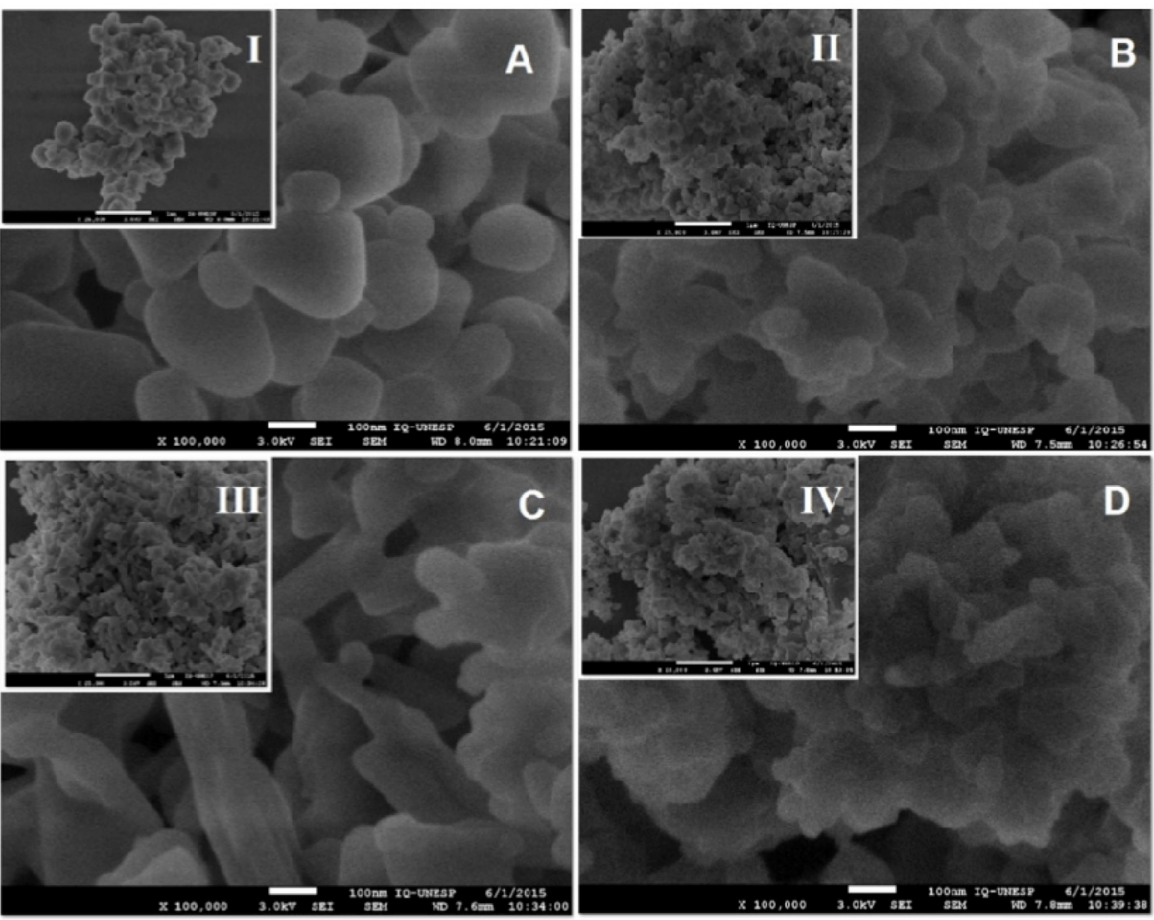

Fig. 5. FEG-SEM image of systems: (A) $\mathrm{ZnH}-1$; (B) $\mathrm{ZnH}-2$, (C) $\mathrm{ZnH}-3$ and (D) $\mathrm{ZnH}-4$ (inset.) 25.000x.

\subsection{Electrocatalytic-oxidation of sulfite by zinc hexacyanoferrate nanoparticles}

To investigate a possible structural and size effect of the particles on the electrocatalytic properties of zinc hexacyanoferrate nanoparticles, a study of voltammetric behavior was conducted.

Initially, nanoparticles of zinc hexacyanoferrate (4 systems) were characterized by cyclic voltammetry using graphite paste electrode $(20 \% \mathrm{w} / \mathrm{w})$ as shown in Fig. 6. A redox couple was observed in all $\mathrm{ZnH}$ systems. The formal potential $\left(\mathrm{E}^{\theta^{\prime}}\right)\left(\mathrm{E}^{\theta^{\prime}}=\mathrm{E}_{\mathrm{ap}}+\right.$ $\mathrm{E}_{\mathrm{cp}} / 2$; where $\mathrm{E}_{\mathrm{ap}}$ and $\mathrm{E}_{\mathrm{cp}}$ are anodic and cathodic peak potentials) was $\left.\mathrm{E}^{\theta^{\prime}}=0.94 \pm 0.01 \mathrm{~V}\left(v=20 \mathrm{mV} \mathrm{s}^{-1} ; \mathrm{KCl} 1.0 \mathrm{M}\right)\right)$ attributed to the redox process $\left[\mathrm{Fe}^{\mathrm{II}}(\mathrm{CN})_{6}\right] /\left[\mathrm{Fe}^{\mathrm{III}}(\mathrm{CN})_{6}\right]$ in the presence of $\mathrm{Zn}^{2+}$. One more broadened voltammogram was found only in the system $\mathrm{ZnH}-1$.

As a practical application of these nanoparticles, a comparative voltammetric study was conducted for the detection of sulfite ion using graphite paste electrode. Fig. 6 illustrates the voltammetric behavior of the modified graphite paste electrode with zinc hexacyanoferrate nanoparticles ( $\mathrm{ZnH}-1, \mathrm{ZnH}-1, \mathrm{ZnH}-3, \mathrm{ZnH}-4$ systems) for the electrocatalytic oxidation of sulfite ion in $1.0 \mathrm{~mol} \mathrm{~L}^{-1} \mathrm{KCl}$. The unmodified graphite paste electrode in a solution of $\mathrm{KCl} 1.0 \mathrm{~mol} \mathrm{~L}^{-1}$ in the absence (curve A) and presence of sulfite (curve $B$ ) did not show a redox couple in the potential range studied between -0.2 and $1.2 \mathrm{~V}$. After the addition of sulfite there was an increase in the anodic peak current intensity at $1.0 \mathrm{~V}$ (curve D) for the $\mathrm{ZnH}-1, \mathrm{ZnH}-3, \mathrm{ZnH}-4$ systems when compared with the modified graphite paste electrode with $\mathrm{ZnH}$ in the absence of sulfite (curve C). Thus, for all systems there was an increase in peak current at $1.0 \mathrm{~V}$. These results demonstrate that these systems may be suitable to develop electrochemical sensors for the detection of sulfite. Thus, for the $\mathrm{ZnH}-3, \mathrm{ZnH}-4$ systems it was determined that by adding aliquots of the sulfite, the analyte was oxidized at the electrode surface by an electrocatalyst oxidation process.
It should be noted that sensitivity was observed only for the $\mathrm{ZnH}-1$ and $\mathrm{ZnH}-2$ systems, whereas for the $\mathrm{ZnH}-3, \mathrm{ZnH}-4$ systems a strong electrocatalytic activity was observed, which were more pronounced for the $\mathrm{ZnH}-4$ system.

The electrocatalytic oxidation of sulfite occurs as follows: $\mathrm{Fe}^{3+}$ produced during anodic scan, chemically oxidize the ion sulfite when it is reduced to $\mathrm{Fe}^{2+}$, which will again be electrochemically oxidized to $\mathrm{Fe}^{3+}[42]$.

The electrocatalytic process in these systems can also be represented according to Eqs. (3) and (4):

$\mathrm{K}_{2} \mathrm{Zn}_{3}{ }^{(\mathrm{II})}\left[\mathrm{Fe}^{(\mathrm{II})}(\mathrm{CN})_{6}\right]_{2} \leftrightarrows \mathrm{Zn}_{3}{ }^{(\mathrm{II})}\left[\mathrm{Fe}^{(\mathrm{III})}(\mathrm{CN})_{6}\right]_{2}+2 \mathrm{~K}^{+}+2 \mathrm{e}^{-}$

$\mathrm{Zn}_{3}{ }^{(\mathrm{II})}\left[\mathrm{Fe}^{(\mathrm{III})}(\mathrm{CN})_{6}\right]_{2}+2 \mathrm{~K}^{+}+\mathrm{SO}_{3}{ }^{2-}+\mathrm{H}_{2} \mathrm{O} \leftrightarrows \mathrm{K}_{2} \quad \mathrm{Zn}_{3}{ }^{(\mathrm{II})}\left[\mathrm{Fe}^{(\mathrm{II})}(\mathrm{CN})_{6}\right]_{2}+$ $\mathrm{SO}_{4}{ }^{2-}+2 \mathrm{H}^{+}$

Thus, sulfite is oxidized at the electrode surface, and this process occurs in the potential of $1.0 \mathrm{~V}$. The oxidation process does not occur in this potential when unmodified graphite paste is used (Fig. 6).

The peak potential is not affected by the concentration of sulfite and the catalytic current is also linear with the square root of the scan rate. This is an indicative that electro oxidation of sulfite by $\mathrm{ZnH}$ is a diffusion-controlled process. Fig. 7 shows the voltammetric behavior of $\mathrm{ZnH}$ after adding different concentrations of sulfite and Fig. 8 illustrates the analytical curve used in the detection of sulfite for $\mathrm{ZnH}-1$ system, $\mathrm{ZnH}-2$ system, $\mathrm{ZnH}-3$ system and $\mathrm{ZnH}-4$ system. Table 2 lists the main electroanalytical parameters obtained for the $\mathrm{ZnH}$ systems. Table 2 clearly shows that the $\mathrm{ZnH}-2$ system exhibits a lower detection limit, but the $\mathrm{ZnH}-3$ system showed a linear response over a wider concentration range. Amperometric sensitivity for systems $\mathrm{ZnH}-1$ and $\mathrm{ZnH}-2$ were 0.026 and $0.031 \mathrm{~A} \mathrm{~mol} \mathrm{~L}^{-1}$,respectively, in other words, about 100 times smaller than the values obtained for the systems $\mathrm{ZnH}-3$ and $\mathrm{ZnH}-4$. 

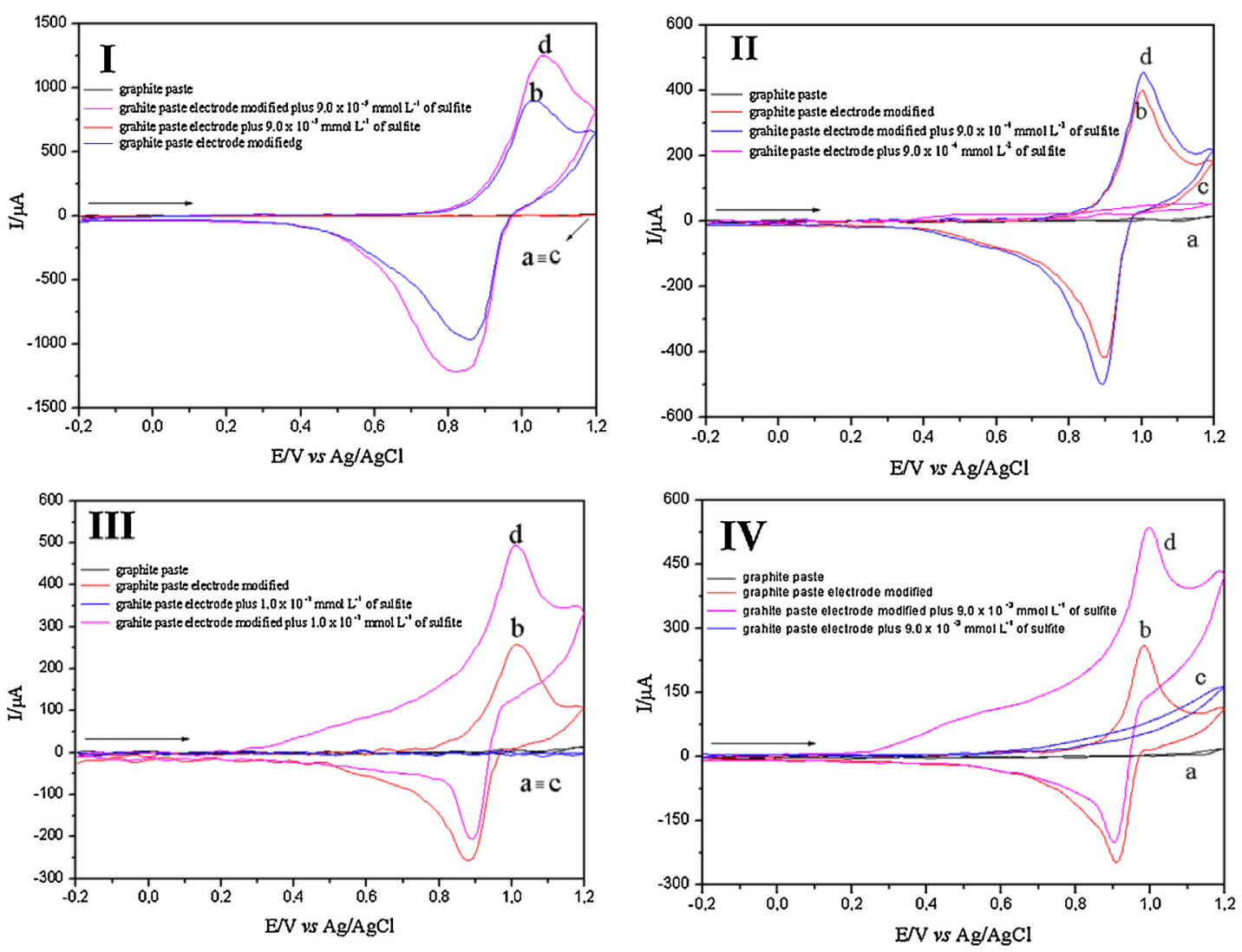

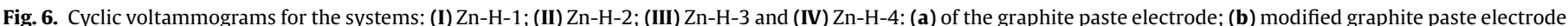

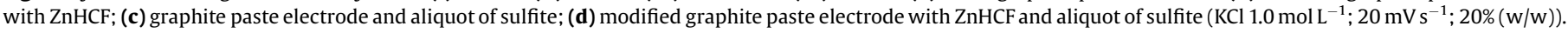
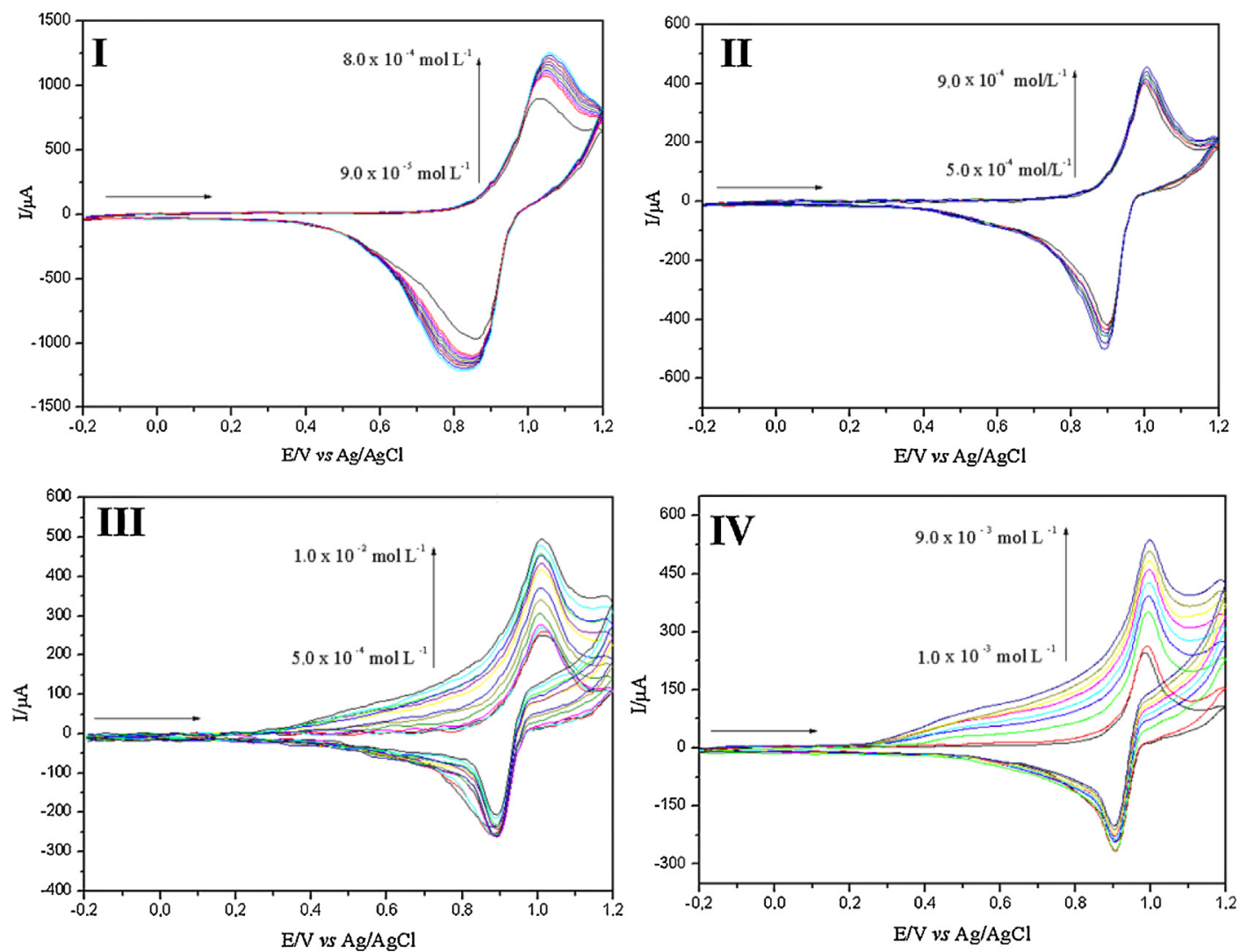

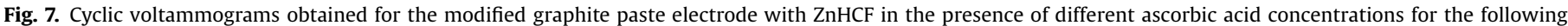

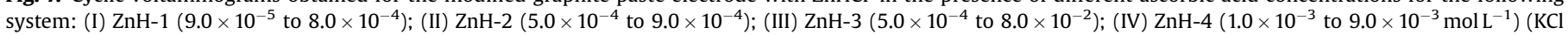
$\left.1.0 \mathrm{~mol} \mathrm{~L}^{-1} ; 20 \mathrm{mV} \mathrm{s}^{-1} ; 20 \%(\mathrm{w} / \mathrm{w})\right)$. 

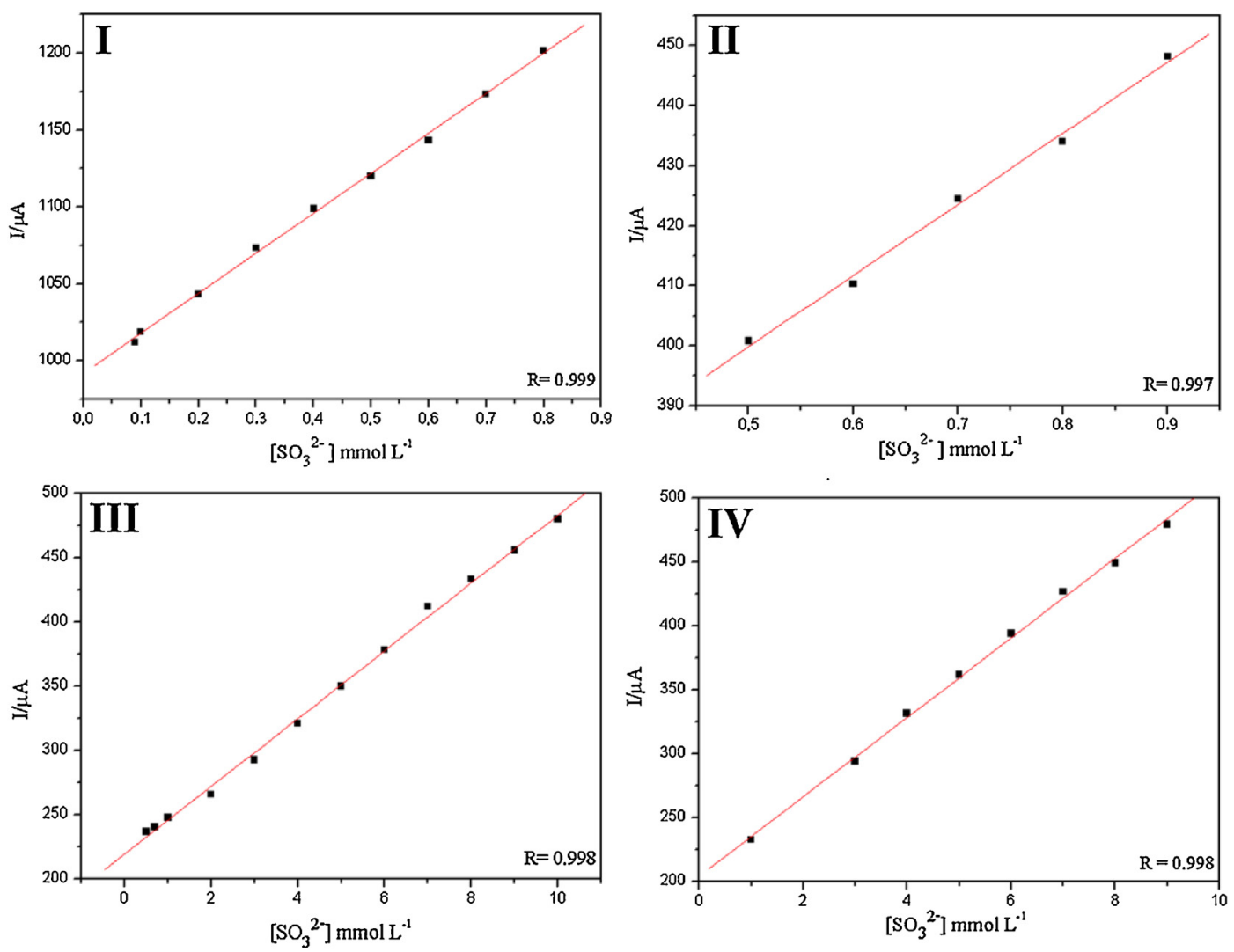

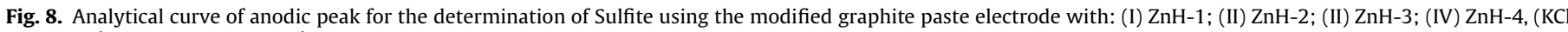
$\left.1,0 \mathrm{~mol} \mathrm{~L}^{-1}, \mathrm{pH} 7,0 ; \mathrm{v}=20 \mathrm{mV} \mathrm{s}^{-1} ; 20 \%(\mathrm{w} / \mathrm{w})\right)$.

Table 2

Parameters of the calibration curve for the detection of Sulfite.

\begin{tabular}{|c|c|c|c|c|c|}
\hline System & Linear Range & $\mathrm{CC}(\mathrm{R})[\mathrm{a}]$ & LOD mol L ${ }^{-1}[\mathrm{~b}]$ & AS A mol L ${ }^{-1}[\mathrm{c}]$ & EC [d] \\
\hline $\mathrm{ZnH}-1$ & $9.0 \times 10^{-5}-8.0 \times 10^{-4}$ & 0.999 & $3.31 \times 10^{-5} \pm 0.07$ & 0.259 & $Y(A)=2.191 \times 10^{-4}+0.259[$ Sulfite] \\
\hline $\mathrm{ZnH}-2$ & $5.0 \times 10^{-4}-9.0 \times 10^{-4}$ & 0.997 & $1.26 \times 10^{-5} \pm 0.05$ & 0.118 & $Y(A)=3.406 \times 10^{-3}+0.118[$ Sulfite $]$ \\
\hline $\mathrm{ZnH}-3$ & $5.0 \times 10^{-4}-1.0 \times 10^{-2}$ & 0.998 & $5.17 \times 10^{-4} \pm 0.04$ & 0.026 & $\mathrm{Y}(\mathrm{A})=2.191 \times 10^{-4}+0.026[$ Sulfite $]$ \\
\hline $\mathrm{ZnH}-4$ & $1.0 \times 10^{-3}-9.0 \times 10^{-3}$ & 0.998 & $3.99 \times 10^{-4} \pm 0.04$ & 0.031 & $Y(A)=2040 \times 10^{-4}+0.031$ [Sulfite] \\
\hline
\end{tabular}

[a] CC=Correlation Coefficient; [b] LOD=Limit of Detection; [c] AS=Amperometric Sensitivity; [d] EC=Equation Calibration; n=3.

Interferences in the determination of $56 \mathrm{ppm}$ sulfite using the modified graphite paste electrode with $\mathrm{ZnH}$ were examined by testing the effect of several species frequently found with sulfite [43]. The corresponding current intensity was compared with those obtained in the absence of each interfering compound.

The effect of several organic acids such as citric acid, oxalic acid, ascorbic acid, and the sugars such as glucose, fructose, sucrose and some inorganic ions such as thiosulfate, persulfate, nitrite, nitrate, acetate, chloride were carried out adding 500 -fold of some of the compounds mentioned. Of the compounds tested, only ascorbic acid and acetate caused a serious negative interference in the electrode response. The other compounds did not show any interference (at 150 fold) to detect sulfite using the modified graphite paste electrode.

The use of these materials achieved a low detection limit for the electroanalytical detection of sulfite, with values close to those previously reported, based on direct determination using biosensors [44,45] or using other chemically modified electrodes [46].

\section{Conclusions}

The $\mathrm{ZnH}$ nanoparticles were synthesized using different volume ratios of formamide and water mixture. The composition and structure of $\mathrm{ZnH}$ systems ( $\mathrm{ZnH}-1$; $\mathrm{ZnH}-2$; $\mathrm{ZnH}-3$ and $\mathrm{ZnH}-4$ ) were confirmed by atomic absorption, FT-IR, UV-vis, XRD, FE-SEM and EDX techniques. The results revealed that the structure of synthesized zinc hexacyanoferrate is very close to $\mathrm{Zn}_{3}[\mathrm{Fe}$ $\left.(\mathrm{CN})_{6}\right]_{2} \cdot 2 \mathrm{H}_{2} \mathrm{O}$. The solvent used can influence the size and chemical structure of nanoparticles.

The cyclic voltammogram of the modified graphite paste electrode for all $\mathrm{ZnH}$ systems showed a well-defined redox couple. The formal potential $\left(\mathrm{E}^{\theta^{\prime}}\right)$ was $=0.94 \pm 0.01 \mathrm{~V}\left(\nu=20 \mathrm{mV} \mathrm{s}^{-1} ; \mathrm{KCl}\right.$ $1.0 \mathrm{M})$ attributed to the redox process $\left[\mathrm{Fe}^{\mathrm{II}}(\mathrm{CN})_{6}\right] /\left[\mathrm{Fe}^{\mathrm{III}}(\mathrm{CN})_{6}\right]$ in presence of $\mathrm{Zn}^{2+}$. The redox couple $\left[\mathrm{Fe}^{\mathrm{II}}(\mathrm{CN})_{6}\right] /\left[\mathrm{Fe}^{\mathrm{III}}(\mathrm{CN})_{6}\right]$ presents pronounced sensitivity and electrocatalytic response for the detection of Sulfite. For the system with a higher formamide concentration $(\mathrm{ZnH}-3 ; \mathrm{ZnH}-4)$ the formation of smaller particles 
and a more pronounceable electrocatalytic response for detection of sulfite was observed. The system with a lower formamide concentration in the media only exhibited sensitivity for the detection of sulfite ( $\mathrm{ZnH}-1 ; \mathrm{ZnH}-2)$.

\section{Acknowledgments}

The authors would like to express their gratitude for the financial support by the Fundação de Amparo à Pesquisa do Estado de São Paulo (FAPESP- Proc. 2012/05438-1 and 2012/11306-0) and Coordenação de Aperfeiçoamento de Pessoal de Nível Superior (CAPES).

\section{References}

[1] B.J. Sanghavi, W. Varhue, J.L. Chávez, C. Choue, N.S. Swami, Electrokinetic preconcentration and detection of neuropeptides at patterned graphenemodified electrodes in a nanochannel, Anal. Chem. 86 (2014) 4120-4125.

[2] R.C. Ashoori, Electrons in artificial atoms, Nature 379 (1996) 413-419.

[3] W. Kosaka, M. Tozawa, K. Hashimoto, S.I. Ohkoshi, Synthesis and superparamagnetic property of a Co-Cr Prussian blue analogue nanoparticles inside Nafion membrane, Inorg. Chem. Commun. 9 (2006) 920-922.

[4] J.M. Domínguez-Vera, E. Colacio, Nanoparticles of Prussian blue Ferritin: a new route for obtaining nanomaterials, Inorg. Chem. 42 (2003) 6983-6985.

[5] L.D. Pachón, G. Rothenberg, Transition-metal nanoparticles: synthesis, stability and the leaching issue, Appl. Organomet. Chem. 22 (2008) 288-299.

[6] L. Zhang, L. Chen, X. Zhou, Z. Liu, Towards high-vltage aqueous metal-ion batteries beyond 1:5 V: the zinc/zinc hexacyanoferrate system, Adv. Energy Mater. 5 (2015) 1614-6832.

[7] R. Trócoli, F. La Mantia, An aqueous zinc-ion battery based on copper hexacyanoferrate, ChemSusChem 8 (2015) 481-485.

[8] N.A. Sitnikova, M.A. Komkova, I.V. Khomyakova, E.E. Karyakina, A.A. Karyakin, Transition metal hexacyanoferrates in electrocatalysis of $\mathrm{H}_{2} \mathrm{O}_{2}$ reduction: an exclusive property of Prussian blue, Anal. Chem. 86 (2014) 4131-4134.

[9] D.R. Do Carmo, M.M. Souza, U.O. Bicalho, V.S. Dos Santos, J.P. Souza, D.R. Silvestrini, Direct preparation and characterization of copper pentacyanonitrosylferrate nanoparticles, J. Nanomater. 2015 (2015) 1-6.

[10] S.R. Ali, V.K. Bansal, A.A. Khan, S.K. Jain, M.A. Ansari, Growth of zinc hexacyanoferrate nanocubes and their potential as heterogeneous catalyst for solvent-free oxidation of benzyl alcohol, J. Mol. Catal. A: Chem. 303 (2009) 60-64.

[11] A.A. Karyakin, Prussian blue and its analogues: electrochemistry and analytica applications, Electroanalysis 13 (2001) 813-819.

[12] D.R. Silvestrini, M.M. Souza, L.R. Cumba, D.R. Do Carmo, Voltammetric determination of sulfite using graphite paste electrode modified with nanoparticles of copper pentacyanonitrosylferrate, ECS Trans. 43 (2012) 217-224.

[13] R.R. Sheha, Synthesis and characterization of magnetic hexacyanoferrate (II) polymeric nanocomposite for separation of cesium from radioactive waste solutions, J. Colloid Interface Sci. 388 (2012) 21-30.

[14] G. Fu, W. Liu, S. Feng, X. Yue, Prussian blue nanoparticles operate as a new generation of photothermal ablation agents for cancer therapy, Chem. Commun. 48 (2012) 11567-11569.

[15] D.R. Do Carmo, D. Franco, U.P. Rodrigues Filho, Y. Gushikem, E. Stadler, V. Drago, The cyanide photoisomerization In zinc hexacyanoferrate (Ii) supported on titanium dioxide-Silica gel composite: a matrix effect, J. Coord. Chem. 54 (2001) 455-468.

[16] A.J. Bard, M. Stratmann, Encyclopaedia of electrochemistry, Inorg Electrochem. 7b (2006) 537.

[17] S.R. Ali, V.K. Bansal, A.A. Khan, S.K. Jain, M.A. Ansari, Growth of zinc hexacyanoferrate nanocubes and their potential as heterogeneous catalyst for solvent-free oxidation of benzyl alcohol, J. Mol. Catal. A: Chem. 303 (2009) 60-64.

[18] J. Balmaseda, E. Reguera, A. Gomez, B. Diaz, M. Autie, Evaluation of cadmium hexacianoferrate(III) as a microporous material, Microporous Mesoporous Mater. 54 (2002) 285-292.

[19] J.R. Hernández, E. Reguera, E. Lima, J. Balmaseda, R.M. García, H.Y. Madeira, An atypical coordination in hexacyanometallates: structure and properties of hexagonal zinc phases, J. Phys. Chem. Solids 68 (2007) 1630-1642.

[20] V.D. Neff, Electrochemical oxidation and reduction of thin films of Prussian blue, J. Electrochem. Soc. 125 (1978) 885-886.
[21] K. Itaya, T. Ataka, S. Toshima, Electrochemical preparation of a Prussian blue analog: iron-ruthenium cyanide, J. Am. Chem. Soc. 104 (1982) 3751-3752.

[22] S. Boopathi, S.S. Kumar, J. Joseph, K.L. Phani, Selective deposition of zinc hexacyanoferrate on the metal impurity sites of a SWCNT/glassy carbon electrode, Electrochem. Commun. 13 (2011) 294-297.

[23] V. Jassal, U. Shanker, B.S. Kaith, S. Shankar, Green synthesis of potassium zinc hexacyanoferrate nanocubes and their potential application in photocatalytic degradation of organic dyes, RSC Adv. 5 (2015) 26141-26149.

[24] A. Eftekhari, Electrochemical behavior and electrocatalytic activity of a zinc hexacyanoferrate film directly modified electrode, J. Electroanal. Chem. 537 (2002) 59-66.

[25] J. Joseph, H. Gomathi, G.P. Rao, Modification of carbon electrodes with zinc hexacyanoferrate, J. Electroanal. Chem. 431 (1997) 231-235.

[26] S. Boopathi, S.S. Kumar, J. Joseph, K.L. Phani, Selective deposition of zinc hexacyanoferrate on the metal impurity sites of a SWCNT/glassy carbon electrode, Electrochem. Commun. 13 (2011) 294-297.

[27] M. Ishizaki, K. Kanaizuka, M. Abe, Y. Hoshi, M. Sakamoto, T. Kawamoto, H. Tanaka, M. Kurihara, Preparation of electrochromic Prussian blue nanoparticles dispersible into various solvents for realisation of printed electronics, Green Chem. 14 (2012) 1537-1544.

[28] A.G. Becerra, F.M. Martínez, M.B. Soto, N. Casillas, I. Ceja, S. Prévost, M. Gradzielski, J.I. Escalante, Preparation of electrochromic Prussian blue nanoparticles dispersible into various solvents for realisation of printed electronics, Green Chem. 14 (2012) 1537-1544.

[29] J. Qiu, J. Liu, K. Sun, Y. Miao, Characterization of Prussian blue nanoparticles prepared by reverse micelle and electrochemical study of their assembly, Surf. Rev. Lett. 16 (2009) 539-544.

[30] X.Z. Bian, H.Q. Luo, N.B. Li, A new material based on nanostructured Prussian blue analogue film doped with $\mathrm{Ce}(\mathrm{III})$ for development of hydrogen peroxide sensor, Electroanalysis 22 (2010) 1364-1368.

[31] L. Catala, A. Gloter, O. Stephan, G. Rogez, T. Mallah, Superparamagnetic bimetallic cyanide-bridged coordination nanoparticles with $T_{\mathrm{B}}=9 \mathrm{~K}$, Chem. Commun. 9 (2006) 1018-1020.

[32] Y. Yue, A.J. Binder, B. Guo, Z. Zhang, Z.A. Qiao, G. Tian, S. Dai, Mesoporous Prussian blue analogues: template-free synthesis and sodium-ion battery applications, Angew. Chem. Int. 53 (2014) 3134-3137.

[33] A.C. García, A.V. Moya, Á. Bernabeu, J.S. González, E. Fernández, P. Botella, Gd-Si oxide mesoporous nanoparticles with pre-formed morphology prepared from a Prussian blue analogue template, Dalton Trans. 44 (2015) 14034-14041.

[34] V. Vo, M.N. Van, H.I. Lee, J.M. Kim, Y. Kim, S.J. Kim, A new route for obtaining Prussian blue nanoparticles, Mater. Chem. Phys. 107 (2008) 6-8.

[35] J.R. Hernández, E. Reguera, E. Lima, J. Balmaseda, R.M. García, H.Y. Madeira, An atypical coordination in hexacyanometallates: structure and properties of hexagonal zinc phases, J. Phys. Chem. Solids 68 (2007) 1630-1642.

[36] K. Nakamoto, Infrared and Raman Spectra of Inorganic and Coordination Complexes, Wiley, New York, 1986

[37] E. Reguera, E. Marín, A. Calderón, A.R. Hernández, Photo-induced charge transfer in Prussian blue analogues as detected by photoacoustic spectroscopy, Spectrochim. Acta Mol. Biomol. Spectrosc. 68 (2007) 191-197.

[38] N.V. Minh, P.K. Phu, I.S. Yang, Nano-sized particles of Prussian blue analogue $\mathrm{KxCoy}\left[\mathrm{Fe}(\mathrm{CN})_{6}\right]$ and $\mathrm{KxNiy}\left[\mathrm{Fe}(\mathrm{CN})_{6}\right]$ : synthesis and their properties, J. Korean Phys. Soc. 53 (2008) 3559-3562.

[39] P.H. Klung, E.L. Alexander, X-ray Diffraction Procedures for Polycystalline and Amorphous Materials, 2nd ed., John Wiley \& Sons, Hoboken, 1974.

[40] S. Adak, L.L. Daemen, H. Nakotte, Negative thermal expansion in the Prussian blue analog $\mathrm{Zn} 3[\mathrm{Fe}(\mathrm{CN}) 6] 2: \mathrm{X}$-ray diffraction and neutron vibrational studies, J. Phys.: Conf. Ser. 251 (2010) 1-4.

[41] M. Perrier, S. Kenouche, J. Long, K. Thangavel, J. Larionova, C. Goze-Bac, A. Lascialfari, M. Mariani, N. Baril, C. Guérin, B. Donnadieu, A. Trifonov, Y. Guari, Investigation on NMR relaxivity of nano-sized cyano-bridged coordination polymers, Inorg. Chem. 52 (2013) 13402-13414.

[42] L.A. Soares, W. Yingzi, T.F.S. Da Silveira, D.R. Silvestrini, U.O. Bicalho, N.L. Dias Filho, D.R. Do Carmo, A cubic silsesquioxane modified with Purpald ${ }^{\mathbb{R}}$ : preparation: characterization and a voltammetric application for determination of sulfite, Int. J. Electrochem. Sci. 8 (2013) 7565-7580.

[43] A.K. Abass, J.P. Hart, D. Cowell, Development of an amperometric sulfite biosensor based on sulfite oxidase with cytochrome c as electron acceptor, and a screen-printed transducer, Sens. Actuator B-Chem. 62 (2000) 148-153.

[44] M.K. Sezgintürk, E. Dinçkaya, Direct determination of sulfite in food samples by a biosensor based on plant tissue homogenate, Talanta 10 (2005) 998-1002.

[45] E. Dinçkaya, M.K. Sezgintürk, E. Akyilmaz, F.N. Ertaș, Sulfite determination using sulfite oxidase biosensor based glassy carbon electrode coated with thin mercury film, Food Chem. 101 (2007) 1540-1544.

[46] L. Junqing S. Jingli, Y. Xi, Z. Xiaoling, T. Zechao, G. Quangui, L. Lang, Preparation and electrochemical properties of hollow nickel oxide fibers int, J. Electrochem. Sci. 7 (2012) 2214-2220. 